\title{
Socioeconomic and demographic factors associated with caesarean section delivery in Southern Ghana: evidence from INDEPTH Network member site
}

Alfred Kwesi Manyeh ${ }^{1,2^{*}}$ D, Alberta Amu ${ }^{1,3}$, David Etsey Akpakli1 ${ }^{1,3}$, John Williams ${ }^{1,3}$ and Margaret Gyapong ${ }^{1,4}$

\begin{abstract}
Background: In recent years, caesarean section rates continue to evoke worldwide concern because of their steady increase, lack of consensus on the appropriate caesarean section rate and the associated short- and long-term risks. This study sought to identify the rate of caesarean section and associated factors in two districts in rural southern Ghana.

Methods: Pregnancy, birth, and socio-demographic information of 4948 women who gave birth between 2011 and 2013 were obtained from the database of Dodowa Health and Demographic Surveillance System. The rate of C-section was determined and the associations between independent and dependent variables were explored using logistic regression. The analyses were done in STATA 14.2 at 95\% confidence interval.

Results: The overall C-section rate for the study period was 6.59\%. Women aged 30-34 years were more than twice likely to have C-section compared to those < 20 year (OR: 2.16, 95\% Cl: 1.20-3.90). However, women aged 34 years and above were more than thrice likely to undergo C-section compared to those < 20 year (OR: 3.73, 95\% Cl: 1.45-5.17). The odds of having C-section was 65 and 79\% higher for participants with Primary and Junior High level schooling respectively (OR: 1.65, 95\% Cl: 1.08-2.51, OR:1.79, 95\%Cl: 1.19-2.70). The likelihood of having C-section delivery reduced by 60, 37, and 35\% for women with parities 2, 3 and 3+ respectively (OR:0.60, 95\% Cl: 0.43-0.83, OR: 0.37, 95\% Cl: 0.25-0.56, OR:0.35, 95\% Cl: 0.25-0.54). There were increased odds of 36, 52, 83\% for women who belong to poorer, middle, and richer wealth quintiles respectively (OR: 1.36, 95\%Cl: 0.85-2.18, OR: 1.52, 95\% Cl: 0.97-2.37, OR: 1.83, 95\% Cl: 1.20-2.80). Participants who belonged to the richest wealth quintile were more than 2 times more likely to have C-section delivery (OR: 2.14, 95\%Cl: 1.43-3.20). The odds of having C-section delivery reduced by 76\% for women from Ningo-Prampram district (OR: 0.76, 95\% Cl: 0.59.0.96). Women whose household heads have Junior High level and above of education were 45\% more likely to have C-section delivery (OR: 1.45, 95\% Cl: 1.09-1.93).
\end{abstract}

Conclusion: Age of mother, educational level, parity, household socioeconomic status, district of residence, and level of education of household head are associated with caesarean section delivery.

Keywords: Caesarean section, INDEPTH network, Dodowa, Ghana

\footnotetext{
* Correspondence: alfredmanyeh4u@gmail.com

${ }^{1}$ Dodowa Health Research Centre, P. O. Box. DD1, Dodowa, Accra, Ghana

${ }^{2}$ Division of Epidemiology and Biostatistics, School of Public Health,

University of the Witwatersrand, Parktown, Johannesburg, South Africa

Full list of author information is available at the end of the article
}

(c) The Author(s). 2018, corrected publication November 2018. Open Access This article is distributed under the terms of the Creative Commons Attribution 4.0 International License (http://creativecommons.org/licenses/by/4.0/), which permits

unrestricted use, distribution, and reproduction in any medium, provided you give appropriate credit to the original author(s) and the source, provide a link to the Creative Commons license, and indicate if changes were made. The Creative Commons Public Domain Dedication waiver (http://creativecommons.org/publicdomain/zero/1.0/) applies to the data made available in this article, unless otherwise stated. 


\section{Background}

Accessibility of comprehensive emergency obstetric care (including caesarean section) is crucial to averting the estimated 2.9 million neonatal and 287,000 maternal mortalities that occur worldwide every year $[1,2]$.

Caesarean section (C-section), is one of the oldest and regularly used surgical procedures in Obstetrics by which fetus is delivered through an abdominal and uterine incision [3-5]. It has been shown that, when C-section is appropriately used, it can improve both infant and maternal health outcomes [6, 7]. According to the World Health Organization (WHO), C-section is a vital treatment in pregnancy [8]. However, the potential risk of $\mathrm{C}$-section may outweigh the benefits when it is used inappropriately $[6,7]$.

In recent years, the number of $\mathrm{C}$-section deliveries has been increasing in developed and developing countries [9-11]. This increase has however not been clinically justified. This worldwide increase in C-section has become a major public health issue due to potential maternal and perinatal risks, inequality of access and cost involved [1217]. According to the $\mathrm{WHO}$ guidelines, no region is justified for having the rate of $\mathrm{C}$-section more than $10-15 \%$ [6, 18]. Despite this WHO guidelines, studies show that the rates of $\mathrm{C}$-sections are high in developing countries [17, 19, 20]. A WHO reports shows that, the global average of C-section rate between 1990 and 2014 increased from 12.4 to $18.6 \%$ [21]. While the $\mathrm{C}$-sections rate varies between 12 and $86 \%$ across studies done in developed countries [22-25] that of developing countries ranges between 2 and 39\% $[8,22,26-29]$. This again shows the cause for concern and hence the need to explore the reasons for the increasing rates in C-section delivery $[6,18]$.

Although there is no evidence of benefits of $\mathrm{C}$-section to mothers or babies who do not need it [30], however, C-section like any surgery, has complications which may persist for a long period after the current delivery and affect the health of the woman, her child, and future pregnancies. According to literature, the global increase in C-section is associated with uterine rupture such that, women with prior who undergo the procedure are more likely to have uterine rupture in future pregnancies [31-35]. The risk of uterine rupture due to prior $\mathrm{C}$-section are higher in population with limited access to comprehensive obstetric care [17, 36, 37].

Studies have attribute the increase in C-sections to multiple factors ranging from the type of health facility, socio-demographic characteristics to maternal health of women [38-43]. These factors include maternal age [3840], birth order [44], birth weight [45], place of residence [14], socioeconomic status, maternal educational level [38, 46-48], former C-section [41-43], obstetric complications [49], maternal request [50], and income level [38, 48]. These factors also vary among different populations [16].

The global increase in the rate of the provision of C-section is reflected in Ghana. According to the 2014
Ghana Demographic and Health Survey (GDHS) survey, the $\mathrm{C}$-section rate in Ghana increased from 4.5 to $6.4 \%$ between 1990 and 2005 [51]. In 2014, the GDHS reported that 13\% of births are delivered by C-section, an increase from $7 \%$ in 2008 [52]. Delivery by C-section is highest among births to women aged 35-49 (17\%); first-parity births (18\%); births for whom women had more than three Antenatal Care (ANC) attendance (15\%); deliveries in urban areas (19\%) and in the Greater Accra region (23\%); births to women with secondary school level and above education (27\%), and those with richest socioeconomic status (28\%) [52].

Primary C-section usually determines the future obstetric course of any woman [53]. Hence there is a need to assess the rate of $\mathrm{C}$-sections and factors contributing to $\mathrm{C}$-section delivery in the context of Ghana using population based data. The existence of a Health and Demographic Surveillance System provided a unique opportunity to study the factors contributing to $\mathrm{C}$-section delivery at the population level. This is because most studies on C-section used hospital based data which were subject to selection bias. The study of determinants of $\mathrm{C}$-section in a population makes it possible to explore how different elements contribute to the decision to perform a C-section. Therefore, this study aimed to examine the rate of $\mathrm{C}$-section delivery and to explore factors associated with the procedure in two rural districts in Ghana.

\section{Methods}

\section{Study area}

This study used secondary data from the Dodowa Health and Demographic Surveillance System (DHDSS). The DHDSS site is in the Shai-Osudoku and Ningo-Prampram districts of the Greater Accra Region of Ghana. The two districts together have a total population of 115,754 people in 380 communities living in 23, 647 households. A detailed description of the DHDSS and its operations can be found elsewhere [54-56]. Health care service delivery in the DHDSS is provided from government hospitals, health centres, clinics, community-based health and planning services (CHPS) compounds/zones, and non-governmental health facilities [54].

\section{Study population}

All mothers who were resident in study area and had a delivery between January 1, 2011 to December 31, 2013 were included in the study. Therefore, all mothers who were outside the study area and those who delivered outside the study date were excluded. A total of 4, 948 women were included in the study.

\section{Variables}

\section{Dependent variable}

The dependent variable is type of delivery and it was dichotomous (coded as 1 if the respondents underwent $\mathrm{C}$-section delivery and 0 if otherwise). 
Table 1 Socio-Demographic Characteristics of the study participants

\begin{tabular}{cll}
\hline Age group & Frequency $^{a}$ & Percentage \\
\hline$<20$ & 552 & 11.16 \\
$20-24$ & 1151 & 23.26 \\
$25-29$ & 1288 & 26.03 \\
$30-34$ & 1061 & 21.44 \\
$34+$ & 896 & 18.11
\end{tabular}

Mean $=28.01(S D=7.06)$

Occupation

Unemployed
Farmer
Artisan

Civil Servant

Student

Others

Level of education

No Education
Primary
JHS /Middle school
SHS and above
Marital status

$\begin{array}{ll}\text { Single } & 1325 \\ \text { Married } & 10 \\ \text { Separated/Divorced } & 99 \\ \text { Cohabiting } & 2437\end{array}$

Parity

Parity 1
Parity 2
Parity 3
Parity $3+$

Timing of ANC visit

First trimester

Second trimester

Third trimester

Type of delivery

Normal delivery

C-Section delivery

Child weight at birth

Low birth weight

Normal birth weight

Not Weighed

Delivery place

Health Facility

Outside Health Facility

$\begin{array}{ll}1125 & 22.74 \\ 855 & 17.28 \\ 608 & 12.29 \\ 1508 & 30.48 \\ 84 & 1.7 \\ 669 & 13.52 \\ 99 & 2\end{array}$

Table 1 Socio-Demographic Characteristics of the study participants (Continued)

\begin{tabular}{lll}
\hline Age group & Frequency $^{a}$ & Percentage \\
\hline $\begin{array}{l}\text { Child gender } \\
\text { Female }\end{array}$ & 2332 & 47.13 \\
Male & 2616 & 52.87 \\
Household heads education & & \\
$\quad$ No education/Primary & 2614 & 52.83 \\
JHS and above & 2334 & 47.17 \\
Household heads gender & & \\
$\quad$ Female & 1893 & 38.26 \\
$\quad$ Male & 3055 & 61.74 \\
District of residence & & \\
Shai-Osudoku & & \\
Ningo-Prampram & 2165 & 53.76 \\
\end{tabular}

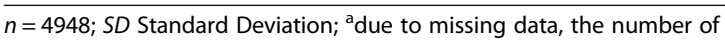

participants is may not be 4948 in all categories

\section{Independent variables}

From available data, the exposure variables included are maternal age, educational level, marital status, parity, timing of ANC visit, place of delivery, child gender and weight at birth, educational level of household head, district of residence and socio-economic status.

The socio-economic status is calculated using the household's social status, ownership of assets, availability of utilities among others using weights derived through a principal component analysis (PCA) [57]. The socioeconomic status is a proxy measure of a household's long term standard of living [54]. The proxies from the PCA were divided into five quintiles; poorest, poorer, middle, richer and richest.

\section{Statistical methods}

A descriptive analysis of socio-demographic characteristics of the participants was carried out. The associations between the exposure variables and the outcome of interest were explored in a crude and adjusted logistics regression model. The exposure variables that were significant at $p<0.05$ in the crude model were entered together into an adjusted model. Stata version 14.2 was used for the analysis and the findings were presented in tables with summary statistics at $95 \%$ confidence intervals $(\mathrm{CI})$.

\section{Results}

Socio-demographic characteristics

Table 1 presents the socio-demographic characteristics of 4948 study participants. The mean age of the study participants was 28 years $(\mathrm{SD}=7.06)$.

While teenagers $(<20$ years) contributed the least proportion of the study participants (11.16\%), the 25-29 age 
group formed the highest proportion (26.03\%) followed by the 20-24 and the 30-34 years' groups which accounted for 23.26 and $21.44 \%$ respectively.

While $30.48 \%$ of the study participants were petty traders, 22.74 and $17.28 \%$ were unemployed and farmers respectively. Students formed $13.52 \%$ of the study participants. Mothers with Junior high school and primary school level contributed 34.18 and $30.36 \%$ respectively.

Participants without formal education accounted for $26.94 \%$ of the study's participants. A large proportion of the study participants had their marital status as cohabiting (50.03\%) while those married, single, and separated /widowed were 20.73, 27.20, and 2.03\% respectively.

Participants with parity 3 or more formed $30.52 \%$ of participants while those with parity 1 and 2 were 26.56 , and $23.91 \%$ respectively.

More than half $(55.21 \%)$ of the study respondents started ANC visit in the first trimester of gestation. Respondents who initiated ANC attendance in the second and third trimesters formed 40.02 and $4.77 \%$ of the sample respectively.

The overall C-section delivery rate for the study period was $6.59 \%$. The C-section rate for Shai-Osudoku District was $7.81 \%$ and that of Ningo-Prampram was $5.64 \% \%$.

The result of this study shows that $55.78 \%$ of the babies were of normal weight. Majority $(67.98 \%)$ of the study participants delivered in a health facility.

Greater proportion of the babies born $(52.87 \%)$ were males. More than half $(52.83 \%)$ of the household heads have no education or primary level of education. As much as $56.24 \%$ of the participants were from the Ningo-Prampram district while $43.76 \%$ were from Shai-Osudoku district.

\section{Crude and adjusted odds ratio of determinants of C- section delivery}

Table 2 presents the crude and adjusted Odds Ratio (OR) at $95 \%$ Confidence Interval $(\mathrm{CI})$ of socioeconomic and demographic factors associated with C-section delivery in Dodowa Health and Demographic Surveillance site.

In the crude model, there was a statistically significant association between maternal age and C-section delivery.

The odds of having C-section delivery by women aged $20-24$ and $25-29$ years is 6 and 43\% respectively more likely compared to those aged < 20 years (OR: $1.06,95 \% \mathrm{CI}$ : 0.66-1.70, OR: 1.43, 95\% CI: 0.91-2.24). Women aged 3034 and $34+$ years were 81 and $74 \%$ respectively more likely to have C-section delivery compared to those aged < 20 years (OR; 1.80, 95\% CI: 1.15-2.84, OR:1.74, 95\% CI: $1.10-2.77)$. This is statistically significant.

A similar relationship is observed after adjusting other explanatory variables such that, the odds of having $\mathrm{C}$-section went up with increasing maternal age. Women aged $30-34$ and $34+$ years were more than twice and thrice more likely respectively to have $\mathrm{C}$-section compared to those aged $<20$ years (OR:2.16, 95\% CI: 1.20 3.90, OR: $3.73,95 \%$ CI: $1.45-5.17)$. This was statistically significant.

The results further revealed that, the odds of women having C-section delivery went up with increasing level of education in both the crude and adjusted models. In the crude model, odds of women with primary level of formal education having C-section delivery was 75\% higher compared to those with no education (OR:1.75, 95\% CI: 1.18-2.59). The odds of women with Junior High School (JHS) level of education having C-section delivery as compared to those with no education is almost three times more likely (OR: 2.79, 95\% CI: $1.93-$ 4.01). Again, the odds of participants with Senior High level of schooling having $\mathrm{C}$-section delivery was eight times more likely compared to those with no formal education (OR: 7.88, 95\% CI: 5.28-11.76).

Holding other variables constant, the odds of having C-section was 65 and $79 \%$ higher for participants with Primary and JHS level of schooling respectively compared to those with no education (OR: 1.65, 95\%CI: 1.08-2.51, OR:1.79, 95\% CI: 1.19-2.70).

In the crude logistics regression model, maternal occupation was statistically significantly associated with $\mathrm{C}$-section. Women who are artisans were more than twice more likely to have $\mathrm{C}$-section compared to those unemployed (OR: 2.37, 95\% CI: 1.63-3.44). This was also statistically significant. Women who were civil servants and women who were engaged in other forms of occupation were more than three and two times more likely to undergo $\mathrm{C}$-sections compared with those who were unemployed (OR: 3.56, 95\% CI: 1.86-6.83, OR:2.43, 95\% CI:1.23-4.81). This is also statistically significant.

Women who were married were $64 \%$ more likely to have C-section delivery (OR: 1.64, 95\% CI: 1.21-2.22) compared to those who are single. This again was statistically significant. For participants with marital status as separated/divorced and cohabiting, the odds of having a C-section reduced to 96 and $84 \%$ respectively compared to those who were single (OR: $0.96,95 \%$ CI: $0.41-2.27$, OR:0.84, 95\% CI: 0.63-1.11). In the adjusted model, participants who were married had increased odds of $26 \%$ of having C-section delivery compared to those who were single (OR: $1.26,95 \% \mathrm{CI}$ : 0.85-1.85).

In the crude model, study participants who started ANC visit in the second and third trimesters were 67 and $15 \%$ respectively less likely to have a C-section compared with those who started their ANC visit in the first trimester (OR: 0.67, 95\% CI: 0.52-0.85, OR: 0.15, 95\% CI: 0.05-0.68). After adjusting other explanatory variables, women who started ANC visit in the third trimester were $24 \%$ less likely to have C-section compared 
Table 2 Crude and adjusted odd ratios of determinates of C-section delivery

\begin{tabular}{|c|c|c|c|c|}
\hline \multirow[t]{2}{*}{ Variable } & \multicolumn{2}{|l|}{ Crude } & \multicolumn{2}{|l|}{ Adjusted $^{b}$} \\
\hline & Odd Ratio (95\% Cl) & $P$-value & Odd Ratio (95\% Cl) & $P$-value \\
\hline \multicolumn{5}{|l|}{ Age group } \\
\hline$<20$ & 1.00 & & 1.00 & \\
\hline $20-24$ & $1.06(0.66-1.70)$ & 0.825 & $1.05(0.64-1.74)$ & 0.839 \\
\hline $25-29$ & $1.43(0.91-2.24)$ & 0.121 & $1.42(0.83-2.43)$ & 0.202 \\
\hline $30-34$ & $1.81(1.15-2.84)^{\mathrm{a}}$ & 0.010 & $2.16(1.20-3.90)^{\mathrm{a}}$ & 0.010 \\
\hline $34+$ & $1.74(1.10-2.77)^{\mathrm{a}}$ & 0.019 & $3.73(1.45-5.17)^{\mathrm{a}}$ & 0.002 \\
\hline \multicolumn{5}{|l|}{ Level of Education } \\
\hline No Education & 1.00 & & 1.00 & \\
\hline Primary & $1.75(1.18-2.59)^{\mathrm{a}}$ & 0.006 & $1.65(1.08-2.51)^{\mathrm{a}}$ & 0.019 \\
\hline Junior High school & $2.79(1.93-4.01)^{\mathrm{a}}$ & $<0.001$ & $1.79(1.19-2.70)^{\mathrm{a}}$ & 0.005 \\
\hline Senior High School and above & $7.88(5.28-11.76)^{a}$ & $<0.001$ & $3.53(2.17-5.73)^{\mathrm{a}}$ & $<0.001$ \\
\hline \multicolumn{5}{|l|}{ Occupation } \\
\hline Unemployed & 1.00 & & 1.00 & \\
\hline Farmer & $1.08(0.72-1.62)$ & 0.706 & $1.01(0.71-1.71)$ & 0.678 \\
\hline Artisan & $2.37(1.63-3.44)^{\mathrm{a}}$ & $<0.001$ & $1.48(0.99-2.20)$ & 0.055 \\
\hline Trader & $1.28(0.91-1.80)$ & 0.159 & $1.36(0.95-1.95)$ & 0.095 \\
\hline Civil Servant & $3.56(1.86-6.83)^{\mathrm{a}}$ & $<0.001$ & $0.78(0.38-1.59)$ & 0.496 \\
\hline Student & $1.34(0.89-2.02)$ & 0.159 & $1.26(0.77-2.05)$ & 0.363 \\
\hline Others & $2.43(1.23-4.81)^{\mathrm{a}}$ & 0.011 & $2.31(1.10-4.85)^{\mathrm{a}}$ & 0.026 \\
\hline \multicolumn{5}{|l|}{ Marital Status } \\
\hline Single & 1.00 & & 1.00 & \\
\hline Married & $1.64(1.21-2.22)^{a}$ & 0.001 & $1.26(0.851-1.85)$ & 0.247 \\
\hline Separated/Divorced & $0.96(0.41-2.27)$ & 0.932 & $1.00(0.37-2.27)$ & 0.856 \\
\hline Cohabiting & $0.84(0.63-1.11)$ & 0.224 & $0.94(0.66-1.32)$ & 0.705 \\
\hline \multicolumn{5}{|l|}{ Parity } \\
\hline Parity 1 & 1.00 & & 1.00 & \\
\hline Parity 2 & $0.74(0.55-0.99)^{\mathrm{a}}$ & 0.045 & $0.60(0.43-0.83)^{\mathrm{a}}$ & 0.002 \\
\hline Parity 3 & $0.57(0.41-0.80)^{\mathrm{a}}$ & 0.001 & $0.37(0.25-0.56)^{\mathrm{a}}$ & $<0.001$ \\
\hline Parity 3+ & $0.51(0.37-0.68)^{a}$ & $<0.001$ & $0.35(0.23-0.54)^{\mathrm{a}}$ & $<0.001$ \\
\hline \multicolumn{5}{|l|}{ Timing of ANC visit } \\
\hline First trimester & 1.00 & & 1.00 & \\
\hline Second trimester & $0.67(0.52-0.85)^{\mathrm{a}}$ & $<0.001$ & $0.81(0.63-1.05)$ & 0.106 \\
\hline Third trimester & $0.15(0.05-0.47)^{\mathrm{a}}$ & $<0.001$ & $0.24(0.07-0.76)^{a}$ & 0.015 \\
\hline \multicolumn{5}{|l|}{ Socio Economic Status } \\
\hline Poorest & 1.00 & & 1.00 & \\
\hline Poorer & $1.12(0.71-1.77)$ & 0.627 & $1.36(0.85-2.18)$ & 0.205 \\
\hline Middle & $1.44(0.93-2.23)$ & 0.099 & $1.52(0.97-2.37)$ & 0.069 \\
\hline Richer & $2.15(1.43-3.23)^{a}$ & $<0.001$ & $1.83(1.20-2.80)^{\mathrm{a}}$ & 0.005 \\
\hline Richest & $3.84(2.62-5.63)^{a}$ & $<0.001$ & $2.14(1.43-3.20)^{a}$ & $<0.001$ \\
\hline \multicolumn{5}{|l|}{ District of residence } \\
\hline Shai-Osudoku & 1.00 & & 1.00 & \\
\hline Ningo-Prampram & $0.71(0.56-0.88)^{\mathrm{a}}$ & 0.002 & $0.76(0.59-0.96)^{\mathrm{a}}$ & 0.024 \\
\hline
\end{tabular}


Table 2 Crude and adjusted odd ratios of determinates of C-section delivery (Continued)

\begin{tabular}{|c|c|c|c|c|}
\hline \multirow[t]{2}{*}{ Variable } & \multicolumn{2}{|l|}{ Crude } & \multicolumn{2}{|l|}{ Adjusted $^{b}$} \\
\hline & Odd Ratio (95\% Cl) & $P$-value & Odd Ratio $(95 \% \mathrm{Cl})$ & $P$-value \\
\hline \multicolumn{5}{|l|}{ Household heads education } \\
\hline No education/Primary & 1.00 & & 1.00 & \\
\hline Junior High School and above & $2.65(2.08-3.38)^{a}$ & $<0.001$ & $1.45(1.09-1.93)^{\mathrm{a}}$ & 0.010 \\
\hline \multicolumn{5}{|l|}{ Household heads gender } \\
\hline Female & 1.00 & & 1.00 & \\
\hline Male & $1.29(1.01-1.64)$ & 0.038 & & \\
\hline \multicolumn{5}{|l|}{ Child weight at birth } \\
\hline Low birth weight & 1.00 & & & \\
\hline Normal birth weight & $0.80(0.48-1.34)$ & 0.404 & & \\
\hline \multicolumn{5}{|l|}{ Child Gender } \\
\hline Female & 1.00 & & & \\
\hline Male & $1.12(0.89-1.41)$ & 0.32 & & \\
\hline
\end{tabular}

SD standard deviation, ${ }^{\text {a }}$ statistical significant, ${ }^{\text {b }}$ Correct classification rate $=93.41 \%$

to those who initiated their ANC visit in the first trimester of pregnancy. This was statistically significant (OR: 0.24, 95\% CI: 0.07-0.76).

The odds of having C-section delivery reduced significantly with increasing parity. There was reduced odds of 74,57 and $51 \%$ of women with parities 2,3 and $3+$ respectively having $\mathrm{C}$-section delivery compared to those with parity 1 (OR: $0.74,95 \%$ CI: $0.55-0.99$, OR: $0.57,95 \%$ CI: $0.41-0.80$, OR:0.51, 95\% CI: 0.37-0.68). In the adjusted model, a similar relationship was observed such that the odds of having $\mathrm{C}$-section delivery reduced with increasing parity. Thus, there was reduced odds of 60,37 , and $35 \%$ for women with parities 2, 3 and 3+ respectively compared with those with parity 1 (OR:0.60, 95\% CI: $0.43-0.83$, OR: 0.37, 95\% CI: 0.25-0.56, OR:0.35, 95\% CI: 0.25-0.54).

The odds of having $\mathrm{C}$-section went up with increasing socioeconomic status. In the crude analysis, participants with middle wealth quintile were $44 \%$ more likely to have C-section (OR: 1.44, 95\%CI:0.93-2.23) compared to those in the poorest group. Participants who belong to the richer and richest quintiles were more than two times and three times more likely to have C-section delivery compared to those who belong to the poorest group (OR: 2.15 , 95\% CI: 1.43-3.23, OR: 3.84, $955 \mathrm{CI}$ : 2.62-5.63). Participants' socioeconomic status continued to be increasingly significantly associated with $\mathrm{C}$-section delivery after adjusting other confounding variables in the adjusted model. There were increased odds of 36 , $52,83 \%$ for women who belong to poorer, middle, and richer wealth quintiles respectively (OR: 1.36, 95\% CI: 0.85-2.18, OR: 1.52, 95\% CI: 0.97-2.37, OR: $1.83,95 \%$ CI: $1.20-2.80)$. Participants who belong to the richest wealth quintile were more than two times more likely to have C-section delivery compared to those who were in the poorest category (OR: 2.14, 95\% CI: 1.43-3.20).
The district where participant resides was significantly associated with C-section delivery such that, there was reduced odds of 71 and $76 \%$ in the crude and adjusted models respectively for women from Ningo-Prampram district compared to those from Shai-Osudoku district (OR:0.71, 95\% CI: 0.56-0.88, OR:0.76, 95\% CI: 0.59.0.96).

While there were increased odds of participants giving birth to male babies having C-section delivery (OR: 1.12, 95\%CI: 0.89-1.41) compared to those with female babies, there was reduced odds of $80 \%$ of having C-section for participants who gave birth to normal weight babies in the crude model (OR: 0.80, 95\% CI: 0.48-1.34) compared to those with low birth weight.

There was a statistically significant association between the level of education of household head and C-section such that participants whose household heads have JHS or more education were more than two times more likely to have $\mathrm{C}$-section in the crude model (OR: 2.65, 95\% CI: 2.08-3.38) compared to those whose heads had primary/no formal education. In the adjusted model, women whose household heads had JHS and above level of formal education were $45 \%$ more likely to have C-section delivery compared to those with primary / no formal education (OR: 1.45, 95\% CI: 1.09-1.93).

\section{Discussion}

Despite the relevance and worldwide interest in this topic, this is the first study in Ghana to have used population based data at the district level to identify the rate and explore factors associated with C-section delivery. Our analysis of data from 4948 research participants revealed that C-section delivery is associated with maternal age, level of education, occupation, parity and ANC visit. The study also showed that other variables associated with $\mathrm{C}$-section 
delivery include socioeconomic status, district of residence and level of education of household head.

The overall C-section rate of $7 \%$ found by the current study is lower than the national rate of $13 \%$ reported in 2014 by GHDS [52]. The current C-section rate is also lower than the WHO recommended rate of $10-15 \%$ [6, 18]. It is however similar to the $7.3 \%$ reported by Betrán $\mathrm{AP}$ et al. for Africa [58] and higher than the 3\% estimated for Western Africa [58].

The findings of our study is consistent with the results of previous studies such that factors such as level of education of women, socio-economic status [38, 46-48, 59, 60], maternal occupation status [33], maternal age [38$40,52,59,61]$, parity $[44,59]$, place of residence [14], and level of education of household head [60] are associated with $\mathrm{C}$-section delivery.

The findings of our study also confirmed the results of GHDS 2014 which suggested that C-section delivery is associated with advanced maternal age (35-49 years), order of births (parity), ANC visit, maternal level of education, and socioeconomic status [52]. The relationship between advanced maternal age and some adverse pregnancy outcomes and higher risk of medical conditions like hypertension and diabetes as shown by other studies $[60,62]$ could explain why increasing maternal age was associated with the increased odds of having C-section delivery in our study.

The lower likelihood of C-section delivery among study participants with increasing parity could mean that many women with three caesarean sections do not get pregnant again to avoid further $\mathrm{C}$-section delivery as established by Nilsen $C$ et al. [63]. This could also be due to the fact that once the woman's pelvis has been tested with a previous pregnancy and delivery, subsequent deliveries tend to be less risky until she reaches her fifth delivery (grand-multipara) when the risk increases again as shown in a previous study [64].

The likelihood of mothers in Shai-Osudoku district having C-section delivery as compared to those from Ningo-Prampram district could be explained by the availability of a district hospital in Shai- Osudoku and three other referral hospital in districts that share boundary with Shai-Osudoku district, therefore providing more ready access to $\mathrm{C}$-sections. This finding corroborates results of other studies which suggest that $\mathrm{C}$-section delivery is associated with availability of and access to a medical facility [65-67].

\section{Strengths and limitations}

The strengths of this study were its data quality and large sample size. Also, being a community based study with focus on rural communities which are priority for public health interventions was a strength of the study. This notwithstanding, the study had a few limitations.
The secondary data used did not include other important variables on maternal health status, evidence of whether the earlier delivery was by caesarean and fetal characteristics that may influence the risk of C-section. The data used was also not a nationally representative one. This is because the two districts cannot be true representative of 216 districts in Ghana hence the limit in the generalizability of the findings.

\section{Conclusion}

The study established that the overall $\mathrm{C}$-section rate in DHDSS site is $6.59 \%$. The findings reinforce the evidence that the odds of having $\mathrm{C}$-section delivery increases with advancing maternal age, level of education and household socioeconomic status. Parity, district of residence, and level of education of household head are other variables that are associated with $\mathrm{C}$-section delivery. To understand other factors influencing $\mathrm{C}$-section delivery and to design an appropriate intervention, we recommend further qualitative research in this area.

\section{Abbreviations}

ANC: Antenatal Care; CHPS: Community-based Health Planning and Services; Cl: Confidence Intervals; DHDSS: Dodowa Health and Demographic

Surveillance System; DHRC: Dodowa Health Research Centre;

EOC: Emergency Obstetric Care; GDHS: Ghana Demographic Health Survey; JHS: Junior High school; MDG: Millennium Development Goal; OR: Odd Ratio; PCA: Principal component analysis

\section{Acknowledgments}

We want thank the study participants, data collectors, and supervisors involved in the work of the DHDSS. We sincerely thank all staff members of DHRC for their contributions to the HDSS and to this study. We would like to extend our special thanks to Professor Margaret Gyapong for always finding the resources to run the HDSS, for her mentorship and advice to the direction of this paper.

\section{Availability of data and materials}

Per institutional policies of DHRC, the datasets used in this study are available on request subject to data sharing agreement.

\section{Authors' contributions}

AKM conceptualized the paper, participated in the study design, conducted the statistical analysis, and led the writing of the paper. AA and DEA contributed intellectual content and insights and contributed to the writing of the manuscript. JW and MG refined the initial study design and critically reviewed the manuscript. All authors read and approved the manuscript.

\section{Ethics approval and consent to participate}

The Ethical Committee of Ghana Health Service and the Institutional Review Board of DHRC approved the data collection techniques and quality assurance of DHDSS. The management of DHRC authorized the use of the DHDSS data for this study on a condition that the identity of the participants remains anonymous.

At the beginning of every update-round of the DHDSS data collection, DHRC sought verbal consent from household heads and participating individuals. All households and individuals who declined to participate were excluded.

Consent for publication Not applicable.

Competing interests

The authors declare that they have no competing interests. 


\section{Publisher's Note}

Springer Nature remains neutral with regard to jurisdictional claims in published maps and institutional affiliations.

\section{Author details \\ 'Dodowa Health Research Centre, P. O. Box. DD1, Dodowa, Accra, Ghana. 2Division of Epidemiology and Biostatistics, School of Public Health, University of the Witwatersrand, Parktown, Johannesburg, South Africa. ${ }^{3}$ Ghana Health Service, Accra, Ghana. ${ }^{4}$ Centre for Health Policy and Implementation Research, Institute for Health Research, University of Health and Allied Sciences, Volta Region, Ho, Ghana.}

\section{Received: 10 October 2017 Accepted: 3 October 2018} Published online: 16 October 2018

\section{References}

1. Neuman MAG, Azad K, et al. Prevalence and determinants of caesarean section in private and public health facilities in underserved south Asian communities: cross-sectional analysis of data from Bangladesh, India and Nepal. BMJ Open. 2014;4:e005982

2. Campbell OM, Graham WJ. Strategies for reducing maternal mortality: getting on with what works. Lancet. 2006;368:1284-99.

3. Joseph PP, Ann MM, Loise JP, Marion S, Rosemary EP. Medical dictionary: a concise and up-to-date guide to medical terms. USA: Houghton Mifflin Company; 1988.

4. Arulkumaran S. Obstetric proceeding: in Dewhurst's textbook of obstetrics and gynecology, 7th ed edn. United States: Edmonds Blackwell publishing 2007.

5. Kwawukume EY: Caesarean section: Asante and Hittcher printing press limited; 2000.

6. Savage W. The caesarean section epidemic. J Obstet Gynaecol. 2000;20:223-5.

7. Panditrao S. Intra-operative difficulties in repeat cesarean sections. J Obstet Gynecol India. 2008;58(6):507-10.

8. World Health Organization: Monitoring emergency obstetric care: a handbook. 2009.

9. Gomes UA, Silva AA, Bettiol H, Barbieri MA. Risk factors for the increasing caesarean section rate in Southeast Brazil: a comparison of two birth cohorts, 1978-1979 and 1994. Int J Epi. 1999;28:687-94.

10. Leone T, Padmadas SS, Matthews Z. Community factors affecting rising caesarean section rates in developing countries: an analysis of six countries. Soc Sci Med. 2008:67:1236-46.

11. Leung GM, Lam TH, Thach TQ, Wan S, Ho LM. Rates of caesarean birth in Hong Kong: 1987-1999. Birth. 2001;28:166-72.

12. Althabe F, Sosa C, Belizan JM, Gibbons L, Jacquerioz F, Bergel E. Cesarean section rates and maternal and neonatal mortality in low-, medium-, and high-income countries: an ecological study. Birth. 2006;33(6):270-7.

13. Betran AP, Merialdi M, Lauer JA, Bing-Shun W, Thomas J, Van Look P, Wagner M. Rates of caesarean section: analysis of global, regional and national estimates. Paediatr Perinat Epidemiol. 2007;21(2):98-113.

14. Stanton CK, Holtz SA. Levels and trends in caesarean birth in the developing world. Stud Fam Plan. 2006;37(1):41-8.

15. Buekens P, Curtis S, Alayon S. Demographic and health surveys: caesarean section rates in sub-Saharan Africa. BMJ. 2003;326(7381):136.

16. Abebe FE, Gebeyehu AW, Kidane AN, Eyassu GA. Factors leading to cesarean section delivery at Felegehiwot referral hospital, Northwest Ethiopia: a retrospective record review. Reprod Health. 2016;13:6.

17. Villar J, Carroli G, Zavaleta N, Donner A, Wojdyla D, World Health Organization 2005 global survey on maternal and perinatal Health Research Group, et al. Maternal and neonatal individual risks and bene ts associated with caesarean delivery: multicentre prospective study. BMJ. 2007:335:1025

18. World Health Organization. Appropriate technology for birth. Lancet. 1985;2: 436-7.

19. Souza JP, Gülmezoglu A, Lumbiganon P, Laopaiboon M, Carroli G. WHO global survey on maternal and perinatal Health Research Group, et al. caesarean section without medical indications is associated with an increased risk of adverse short-term maternal outcomes: the 2004-2008 WHO global survey on maternal and perinatal health. BMC Med. 2010;8:71

20. World Health Organization. Indicator to monitor maternal goals: report of a technical working group. Geneva: World Health Organization; 1994.
21. Betran AP, Ye J, Moller AB, Zhang J, Gumezoglu AM, Torloni MR. The increasing trend in cesarean section rates: global, regional, and national estimates :1990-2014. PLoS One. 2016;11(2):e148343.

22. Adnan $\mathrm{A}, \mathrm{Abu} \mathrm{O}$, Suleiman $\mathrm{H}, \mathrm{Abu} \mathrm{A}$. Frequency rate and indications of cesarean sections at Prince Zaid bin Al Hussein Hospital - Jordan. J Med Sci Clin Res. 2012;19(1):82-6.

23. Lauer JA, Betrán AP, Merialdi M, Wojdyla D. Rates of caesarean section: analysis of global, regional and national estimates. Paediatr Perinatal Epidemiol. 2007;28:98-113.

24. Francome C, Savage W. Caesarean section in Britain and the United States $12 \%$ or 24\%: is either the right rate? Soc Sci Med. 1993;37:1199-218.

25. Thomas J, Paranjothy S. Royal College of Obstetricians and Gynaecologists: clinical effectiveness support unit. The National Sentinel Caesareans section audit report. In. London: RCOG Press; 2001.

26. Shamshad B. Factors leading to increased cesarean section rate. Gomal J Med Sci. 2008;6:1.

27. Belizán J, Althabe F, Barros F, Alexander S. Rates and implications of caesarean sections in Latin America: ecological study. BMJ. 1999;319:1397-400.

28. Lauer J, Betrán A. Decision aids for women with a previous caesarean section: focusing on women's preferences improves decision making. BMJ. 2007:334:1281-2.

29. Najmi R, Rehan N. Prevalence and determinants of caesarean section in a teaching hospital of Pakistan. J Obstet Gynaecol. 2000;20:479-83.

30. Betran AP, Torloni MR, Zhang JJ, Gülmezoglu AM, WHO Working Group on Caesarean Section, Aleem HA, Althabe F, Bergholt T, de Bernis L, Carroli G, Deneux-Tharaux C. WHO Statement on caesarean section rates. BJOG. 2016; 123(5):667-70.

31. Ahmed SM, Daffalla SE. Incidence of uterine rupture in a teaching hospital, Sudan. Saudi Med J. 2001;22:757-61.

32. Eze JN, Ibekwe PC. Uterine rupture at a secondary hospital in Afikpo, Southeast Nigeria. Singap Med J. 2010;51:506-11.

33. Omole-Ohonsi A, Attah R. Risk factors for ruptured uterus in a developing country. Gynecol Obstetric. 2011;21:102. https://doi.org/10.4172/2161-0932. 1000102.

34. Berhe Y, Wall LL. Uterine rupture in resource-poor countries. Obstet Gynecol Surv. 2014:69:695-707.

35. Motomura K, Ganchimeg T, Nagata C, Ota E, Vogel PJ, Betran PA, Torlon RM, Jayaratne K, Jwa CS, Mittal S, et al. Incidence and outcomes of uterine rupture among women with prior caesarean section: WHO multicountry survey on maternal and newborn health. Sci Rep. 2017:7:44093.

36. Lumbiganon P, Laopaiboon M, Gulmezoglu AM, Souza JP, Taneepanichskul $\mathrm{S}$, Ruyan $\mathrm{P}$, et al. Method of delivery and pregnancy outcomes in Asia: the WHO global survey on maternal and perinatal health 2007- 08. Lancet. 2010; 375:490-9.

37. Souza JP, Gulmezoglu A, Lumbiganon P, Laopaiboon M, Carroli G, Fawole B, et al. Caesarean section without medical indications is associated with an increased risk of adverse short-term maternal outcomes: the 2004-2008 WHO global survey on maternal and perinatal health. BMC Med. 2010;8:71

38. Kun $H$, FangbiaoT BF, Joanna $R$, Rachel $T$, Shenglan $T$, et al. A mixedmethod study of factors associated with differences in caesarean section rates at community level: the case of rural China. Midwifery. 2013;29(8):911-20.

39. Parrish KM, Holt VL, Easterling TR, Connell FA, LoGerfo JP. Effect of changes in maternal age, parity, and birth weight distribution on primary caesarean delivery rates. J Am Medi Asso. 1994:271:443-7.

40. Ecker JL, Chen KT, Cohen AP, Riley LE, Lieberman ES. Increased risk of caesarean delivery with advancing maternal age: indications and associated factors in nulliparous women. Am J Obstet Gynaecol. 2001;185:883-7.

41. Lynch CM, Kearney R, Turner MJ. Maternal morbidity after elective repeat caesarean section after two or more previous procedures. Eur J Obstet Gynaecol Reprod Biol. 2002;4320:1-4.

42. Signorelli C, Cattaruzza MS, Osborn JF. Risk factors for caesarean section in Italy: results of a multicentre study. Public Health. 1995;109:191-9.

43. Spaans WA, Sluiijs MB, Van Roosmalen J, Bleker O. Risk factors at caesarean section and failure of subsequent trial of labour. Eur J Obstet Gynaecol Reprod Biol. 2002:100:163-6.

44. Mossialos E, Allin S, Karras K, Davaki K. An investigation of caesarean section in three greek hospitals: the impact of financial incentives and convenience. Eur J Public Health. 2005;15:288-95.

45. Onwude JL, Rao S, Selo-Ojeme DO. Large babies and unplanned caesarean delivery. Eur J Obstet Gynaecol Reprod Biol. 2005;118(1):36-9. 
46. Skalkidis Y, Petridou E, Papathoma E, Revinthi K, Tong D, Trichopoulos D. Are operative delivery procedures in Greece sociallyconditioned? IntJ Qual Health Care. 1996;8:159-65.

47. Taffel SM. Cesarean delivery in the United States, 1990. Vital Health Stat 21. 1994;(51):1-24

48. Tatar M, Gunalp S, Somunoglu S, Demirol A. Women's perceptions of caesarean section: reflections from a Turkish teaching hospital. Soc Sci Med. 2000;50:1227-33.

49. Weiss JL, Malone FD, Emig D, Ball RH, Nyberg DA, Comstock CH, Saade G, Eddleman K, Carter SM, Craigo SD, Carr SR. Obesity, obstetric complications and cesarean delivery rate-a population-based screening study. Am J Obstet Gynecol. 2004;190(4):1091-7.

50. Druzin ML, El-Sayed YY. Caesarean delivery on maternal request: wise use of finite resources? A view from the trenches review article. Semin Perinatol. 2006:30(5):305-8.

51. Tuncalp O, Stanton C, Castro A, Adanu R, Heymann M, et al. Measuring coverage in MNCH: validating Women's self-report of emergency cesarean sections in Ghana and the Dominican Republic. PLoS One. 2013;8(5):e60761.

52. Ghana Statistical Service (GSS), Ghana Health Service (GHS), ICF International. Ghana Demographic and Health Survey 2014. Rockville: GSS, GHS, ICF International; 2015.

53. Hafeez M, Yasin A, Badar N, Pasha Ml, Akram N, Gulzar B. Prevalence and indication of caesarean section in a teaching hospital. JIMSA. 2014;27(1):15-6.

54. Manyeh KA, Kukula V, Odonkor G, Ekey RA, Adjei A, Narh-Bana S, Akpakli DE, Gyapong M. Socioeconomic and demographic determinants of birth weight in southern rural Ghana: evidence from Dodowa health and demographic surveillance system. BMC Pregnancy and Childbirth. 2016;16:160.

55. Awini E, Sarpong D, Adjei A, Manyeh AK, Amu A, Akweongo P, Adongo P, Kukula V, Odonkor G, Narh S, Gyapong M. Estimating cause of adult (15+ years) death using InterVA-4 in a rural district of southern Ghana. Glob Health Action. 2014;7(1):25543.

56. Gyapong M, Sarpong D, Awini E, Manyeh KA, Tei D, Odonkor G, Agyepong IA, Mattah P, Wontuo P, Attaa-Pomaa M, et al. Health and demographic surveillance system profile: the Dodowa HDSS. Int J Epidemiol. 2013;42:1686-96.

57. Vyas S, Kumaranayake L. Constructing socio-economic status indices: how to use principal components analysis. Health Policy Plan. 2006;21(6):459-68.

58. Betrán AP, Ye J, Moller A-B, Zhang J, Gülmezoglu AM, Torloni MR. The increasing trend in caesarean section rates: global, regional and National Estimates: 1990-2014. PLoS One. 2016;11(2):e0148343.

59. Janoudi G, Kelly S, Yasseen A, Hamam H, Moretti F, Walker M. Factors associated with increased rates of caesarean section in women of advanced maternal age. J Obstet Gynaecol Can. 2015;37(6):517-26.

60. Zgheib SM, Kacim M, Kostev K. Prevalence of and risk factors associated with cesarean section in Lebanon - A retrospective study based on a sample of 29,270 women. Women Birth. 2017;30(6):e265-e71.

61. Ji H, Jiang $H$, Yang $L$, et al. Factors contributing to the rapid rise of caesarean section: a prospective study of primiparous Chinese women in Shanghai. BMJ Open. 2015;5:e008994.

62. Luke B, Brown MB. Elevated risks of pregnancy complications and adverse outcomes with increasing maternal age. Hum Reprod. 2007:22(5):1264-72.

63. Nilsen C, Østbye T, Daltveit KA, Mmbaga TB, Sandøy IF. Trends in and sociodemographic factors associated with caesarean section at a Tanzanian referral hospital, 2000 to 2013. Int J Equity Health. 2014;13:87.

64. Mgaya AH, Massawe SN, Kidanto HL, Mgaya HN. Grand multiparity: is it still a risk in pregnancy? BMC Pregnancy Childbirth. 2013;13:241.

65. Lumbiganon P, Laopaiboon M, Gülmezoglu AM, et al. World health organization global survey on maternal and perinatal Health Research Group. Method of delivery and pregnancy outcomes in Asia: the WHO global survey on maternal and perinatal health 2007-08. Lancet. 2010;375:490-9.

66. Shah A, Fawole B, M'Imunya JM, et al. Cesarean delivery outcomes from the WHO global survey on maternal and perinatal health in Africa. Int J Gynaecol Obstet. 2009;107:191-7.

67. Zhu LP, Qin M, Shi DH, et al. Investigation of cesarean section in Shanghai and effect on maternal and child health. Matern Child Health Care China. 2001:16:763-4.

\section{Ready to submit your research? Choose BMC and benefit from:}

- fast, convenient online submission

- thorough peer review by experienced researchers in your field

- rapid publication on acceptance

- support for research data, including large and complex data types

- gold Open Access which fosters wider collaboration and increased citations

- maximum visibility for your research: over $100 \mathrm{M}$ website views per year

At BMC, research is always in progress.

Learn more biomedcentral.com/submissions 